\title{
Photochemistry and photophysics of coordination compounds of the main group metals
}

\author{
A. Vogler* and H. Nikol \\ Institut für Anorganische Chemie, Universität Regensburg, Universitätsstraße 31, \\ D-8400 Regensburg
}

\begin{abstract}
The photoproperties of main group metal complexes with the electron configurations $\mathrm{s}^{2}$ (e.g. $\left.\mathrm{Tl}^{+}, \mathrm{Sb}^{3+}, \mathrm{Te}^{4+}\right)$ and $\mathrm{s}^{0}\left(\right.$ e.g. $\mathrm{Tl}^{3+}, \mathrm{Pb}^{4+}$ ) were studied on the basis of a general concept which relates characteristic excited states to typical photophysical and photochemical processes. The photochemistry is dominated by metalcentered $\mathrm{sp}\left(\mathrm{s}^{2}\right)$ and ligand to metal charge transfer $\left(\mathrm{s}^{0}\right)$ excited states which are capable of inducing inter- and intramolecular redox reactions.
\end{abstract}

\section{INTRODUCTION}

The photophysics and photochemistry of transition metal complexes has become an important branch of inorganic chemistry as well as photochemistry. ${ }^{1}$ The excited state properties of these compounds are now fairly well understood. On the contrary, very little is known about the photophysics and photochemistry of coordination compounds of the main group metals. ${ }^{2}$ Although this lack of knowledge seems to be quite surprising there are some obvious reasons which hamper the study of main group metal complexes. Frequently, these compounds are kinetically labile and can exist with variable coordination numbers and structures in the solid state and in solution. In addition, the structures of many complexes deviate from highly symmetrical geometries. These properties complicate the spectroscopic identification and characterization of main group metal complexes. On the other side, there are also features which facilitate the investigation of these compounds. Since the valence shell includes only $s$ and $p$ orbitals the $\mathrm{d}$ orbitals have not to be considered for low-energy electronic transitions. Compared to transition metals the variation of stable oxidation states of main group metals is much smaller. This confines the number of possible products which may be generated in photoredox reactions. A few years ago we started a systematic investigation of the photophysics and photochemistry of the main group metal complexes. ${ }^{2}$ In this short account it is not attempted to treat this subject comprehensively. The current state is illustrated by a few selected examples.

\section{STRUCTURE AND BONDING}

Before we enter the discussion of the photoproperties it is appropriate to give a short description of the structure and bonding of main group metal complexes. These compounds can be classified according to the electron configuration of the free main group metal ions. The $s^{0}$ and $s^{2}$ configurations are most important and correspond to the highest oxidation states and those which are smaller by two units, respectively. The other configurations such as $s^{1}, s^{2} p^{2}$ and $s^{2} p^{4}{ }^{2}$ are less important and will not be discussed here.

Generally, $\mathrm{s}^{0}$ ions form highly symmetrical complexes and their bonding pattern is illustrated by a qualitative MO scheme of an octahedral complex (Figure 1). ${ }^{3}$ The $\pi$ interaction is omitted for clarity. The six ligands are kept to the metal by only four bonds. 


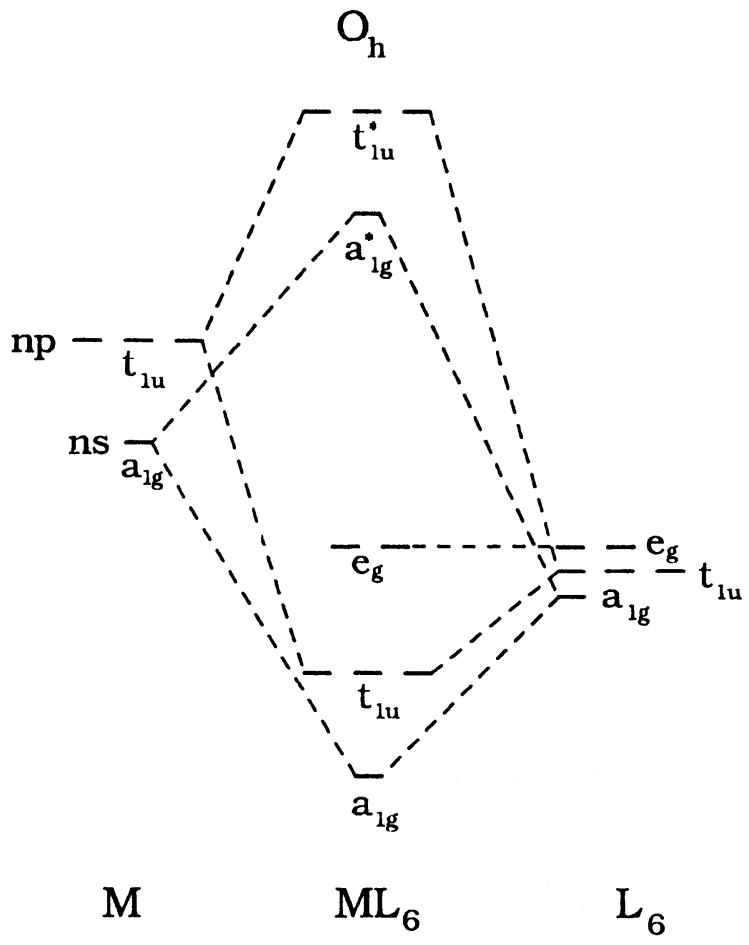

Figure 1 Qualitative MO-scheme of an octahedral complex; $\pi$ orbitals of the ligands are omitted.

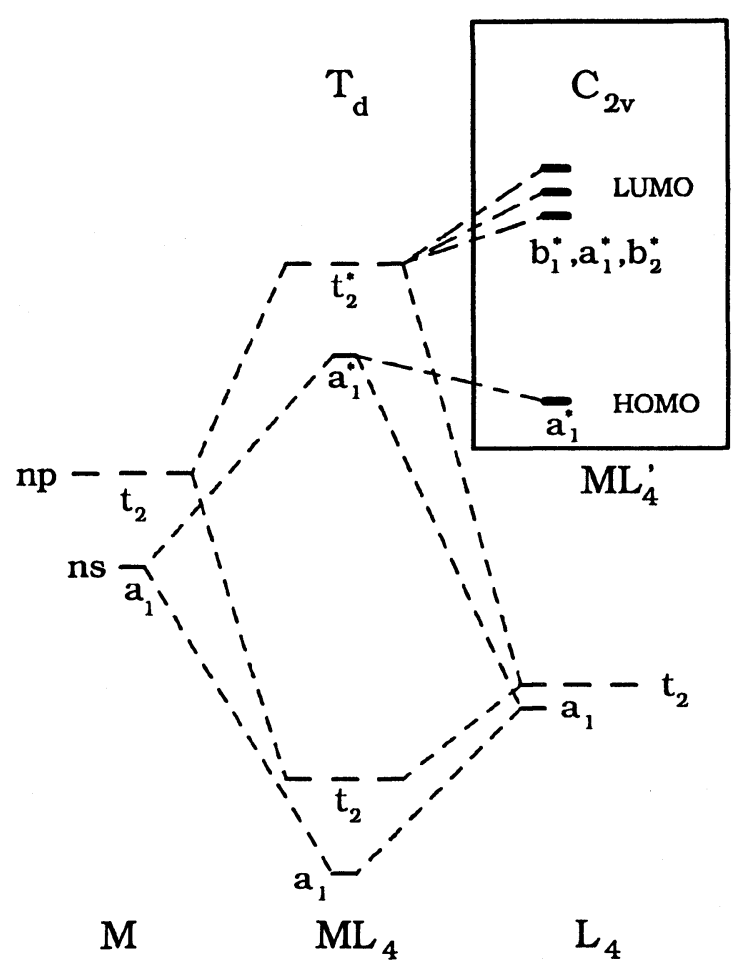

Figure 2 Qualitative MO-scheme of $\mathrm{SbCl}_{4}{ }^{-}$in $T_{d}$ and $C_{2 v}$ (disphenoidal structure) symmetry; $\pi$ orbitals of the ligands are omitted.

In the case of $\mathrm{s}^{2}$ ions two valence electrons enter the antibonding $\mathrm{a}_{1 \mathrm{~g}}{ }^{*}$ orbital (Figure 1) and reduce the metal-ligand bond order to three. However, in accordance with Gillespie's and Nyholm's VSEPR model ${ }^{4}$ most $s^{2}$ complexes undergo a second order Jahn-Teller distortion which stabilizes the antibonding HOMO. ${ }^{3}$ For example, a highly symmetrical, tetrahedral $s^{2}$ complex such as $\mathrm{SbCl}_{4}{ }^{-}$is not stable but converted to a disphenoidal (seesaw) structure (Figure 2 ). This distortion is associated with $\mathrm{sp}$ orbital mixing. As a consequence both antibonding $\mathrm{s}^{2}$ electrons are not only stabilized but become also stereochemically active by the admixture of $p$ character. ${ }^{3}$

\section{ELECTRONIC ABSORPTION SPECTRA}

Although our knowledge of the absorption spectra of main group metal complexes is rather limited some important results have been collected and critically reviewed by C. K. J $\phi$ rgensen. ${ }^{5}$ Spectral studies of solids which contain main group metal ions provide an additional source. 6,7

Owing to the empty valence shell simple complexes of $s^{0}$ ions display only ligand to metal charge transfer (LMCT) bands in their absorption spectra. Typical examples are the octahedral anions $\mathrm{SnCl}_{6}{ }^{2-}$ and $\mathrm{PbCl}_{6}{ }^{2-}$. The allowed lowest-energy LMCT transition involves the promotion of an electron from the ligand orbitals to the antibonding $\mathrm{a}_{1 \mathrm{~g}}{ }^{*}$ s-orbital at the metal (Figure 1). Since the oxidation strength of $\mathrm{s}^{0}$ ions increases from the top to the bottom of the main groups the LMCT band of $\mathrm{PbCl}_{6}{ }^{2-}$ (Figure 3) appears at longer wavelength $\left(\lambda_{\max }=318\right.$ $\mathrm{nm} ; \varepsilon=10000)$ than that of $\mathrm{SnCl}_{6}{ }^{2-}\left(\lambda_{\max }=228 \mathrm{~nm} ; \varepsilon=13500\right) .{ }^{8}$ Recently, it has been suggested that this shift, which causes the yellow colour of the lead complex, is caused by relativistic effects. ${ }^{9}$

The absorption spectra of simple $s^{2}$ complexes can be analyzed in terms of the $s \rightarrow p$ transitions of the free $s^{2}$ ion ${ }^{6,7}$ (Figure 4). The ${ }^{1} \mathrm{~S}_{0} \rightarrow{ }^{3} \mathrm{P}_{0}$ transition is strongly forbidden and 


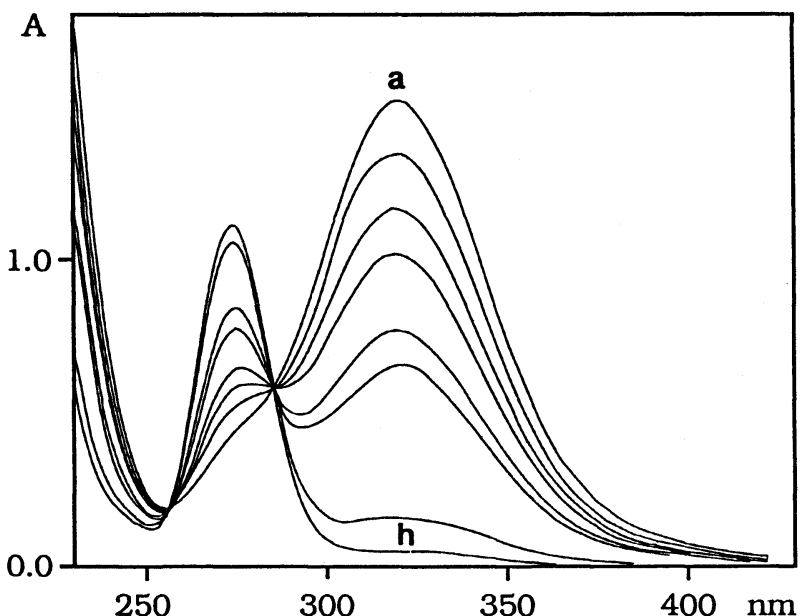

Figure 3 Spectral changes during the photolysis of $1.55 \cdot 10^{-4} . \mathrm{M}\left[\mathrm{NBu}_{4}\right]_{2} \mathrm{PbCl}_{6}$ in $\mathrm{CH}_{3} \mathrm{CN}$ at (a) 0,20 , $60,150 \mathrm{~s}, 6,12,25$ and $35 \mathrm{~min}(\mathrm{~h})$ irradiation time, with $\lambda_{\text {irr }}=313 \mathrm{~nm} ; 1-\mathrm{cm}$ cell.

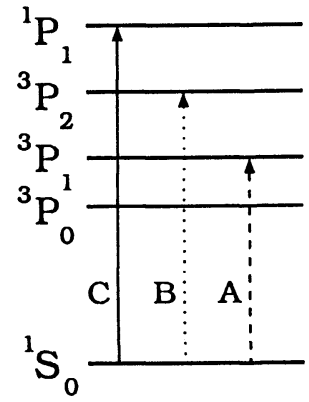

Figure 4 Energy level scheme of a free $s^{2}$ ion.

not observed. The spin-forbidden transitions to the ${ }^{3} \mathrm{P}_{1}$ and ${ }^{3} \mathrm{P}_{2}$ levels give rise to the so-called $\mathrm{A}$ and $\mathrm{B}$ bands which are of moderate intensity. The $\mathrm{C}$ band is more intense and belongs to the spin-allowed ${ }^{1} \mathrm{~S}_{0} \rightarrow{ }^{1} \mathrm{P}_{1}$ transition. The energy and intensity of these bands depend on the central metal, the ligands and the structure of the complexes. In the case of $\mathrm{SbCl}_{4}^{-}$(Figure 2) these bands appear as shoulders (Figure 5) at $\lambda_{\max }=283 \mathrm{~nm}(\mathrm{~A}), 255 \mathrm{~nm}(\mathrm{~B})$ and $235 \mathrm{~nm}(\mathrm{C}) .^{10}$

In addition to the metal-centered sp bands LMCT absorptions may appear at shorter wavelength if the metal ion is oxidizing. The corresponding transitions terminate at the empty $\mathrm{p}$ orbitals. For example, $\mathrm{TeCl}_{6}{ }^{2-}$ displays the longest-wavelength LMCT band ( $\mathrm{t}_{1 \mathrm{u}}$ (ligand) $\rightarrow \mathrm{t}_{1 \mathrm{u}}{ }^{*}$ (p), Figure 1) at $\lambda_{\max }=255 \mathrm{~nm} .{ }^{11,12}$

Frequently $\mathrm{s}^{2}$ ions are not oxidizing but reducing. Complexes are then expected to show longwavelength metal to ligand charge transfer (MLCT) bands if the ligands provide empty orbitals at low energies. Accordingly, compounds such as $\mathrm{M}^{\mathrm{III}}\left(2,2^{\prime}\right.$-bipyridine $) \mathrm{X}_{3}$ with $\mathrm{M}=\mathrm{Sb}, \mathrm{Bi}$ and $\mathrm{X}=$ $\mathrm{Cl}, \mathrm{Br}, \mathrm{I}$ are coloured owing to the presence of such MLCT bands in the visible region. ${ }^{13}$ So far a detailed study of these interesting compounds has been hampered by their instability in solution.

\section{PHOTOPHYSICS}

LMCT excited states are generally not luminescent. In accord with this rule $\mathrm{s}^{0}$ complexes have not been observed to emit. On the contrary, $s^{2}$ complexes are frequently emissive even under ambient conditions. ${ }^{2}$ In 1940 Pringsheim and Vogels reported their pioneering discovery of the photoluminescence of $\mathrm{Tl}^{+}, \mathrm{Sn}^{2+}$, and $\mathrm{Pb}^{2+}$ in aqueous solution. ${ }^{14}$ In the meantime the emission of various $\mathrm{s}^{2}$ ions in solid matrices has been studied in detail ${ }^{7,15}$ while the solution luminescence of $s^{2}$ complexes has been largely ignored. Since $s^{2}$ complexes are often dissociated and thus not well defined in aqueous solution we studied these compounds in non-aqueous solution with solvents of low coordinating ability. The results are not only quite interesting in their own right but also rather valuable with regard to other aspects of the chemistry of main group metals.

As discussed above the absorption bands of $s^{2}$ complexes can be assigned to the electronic transitions of the free $s^{2}$ ions. The photoluminescence of $s^{2}$ complexes which originates from the ${ }^{3} \mathrm{P}$ sp excited state shows, however, a large Stokes shift. Consequently, the emitting species is not a largely unperturbed $s^{2}$ ion but a molecule with a structure which is quite different from that of the ground state. 
The electronic spectra of $\mathrm{SbCl}_{4}{ }^{-}$(Figure 5) ${ }^{10}$ may be used to illustrate this emission behavior. We suggest that the ground state distortion of $\mathrm{SbCl}_{4}{ }^{-}$is eliminated in the excited state. The stabilization of the seesaw structure $\left(C_{2 v}\right.$, Figure 2$)$ is essentially lost in the sp excited state which rearranges toward a symmetrical tetrahedral geometry. Such a structural change is now consistent with the huge Stokes shift of $\mathrm{SbCl}_{4}{ }^{-}$. The ${ }^{3} \mathrm{P}_{1} \rightarrow{ }^{1} \mathrm{~S}_{0}$ phosphorescence which is associated with a restoration of the distortion occurs with a rate $\mathrm{k}=8.3 \cdot 10^{5} \mathrm{~s}^{-1}$.

Recently, we extended these luminescence studies to the complex ions $\mathrm{M}^{\mathrm{III}_{C l_{3}}}{ }^{-}(\mathrm{M}=\mathrm{Ge}, \mathrm{Sn}$, $\mathrm{Pb}$ ) which are trigonal pyramidal $\left(\mathrm{C}_{3 \mathrm{v}}\right)$ in the ground state and rearrange toward a highly symmetrical trigonal planar $\left(\mathrm{D}_{3 \mathrm{~h}}\right)$ structure in the sp excited state. ${ }^{16}$ An analogous approach has been used before in solid state chemistry. Blasse et al. have shown that $\mathbf{s}^{2}$ ions doped into host crystals may also undergo emissions with large Stokes shifts if the ions occupy off-center positions in large interstices since these $\mathrm{s}^{2}$ ions can move toward the center in the sp excited state. ${ }^{15}$ In conclusion, it is remarkable that the elimination of the distortion in the excited state of $s^{2}$ complexes is quite opposite to the behavior of most transition metal complexes which are rather symmetrical in the ground state but distorted in their excited states.

\section{PHOTOCHEMISTRY}

Ligand substitutions and redox processes are the most important photoreactions of transition metal complexes. ${ }^{1}$ Both reactions may also occur simultaneously as coupled processes. Reductive eliminations and oxidative additions belong to this category.

Photosubstitutions of main group metal complexes could also occur but are not expected to yield stable products. Owing to the kinetic lability a ligand substitution or dissociation would be followed by a facile regeneration of the starting complex. Consequently, main group metal complexes will mainly undergo photoredox reactions. Frequently, $s^{0}$ and $s^{2}$ complexes are interconverted. In many cases these two-electron redox processes are accompanied by a change of the coordination number. Reductive eliminations and oxidative additions are thus common photoreactions of main group metal complexes.

Complexes of $s^{0}$ metals are characterized by low-energy LMCT states. In accordance with the nature of this excited state the metal undergoes a reduction and the ligand an oxidation. The reductive elimination of the octahedral anion $\mathrm{PbCl}_{6}{ }^{2-}$ is a typical example of the photoreactivity of $\mathrm{s}^{0}$ complexes. LMCT excitation is followed by the elimination of $\mathrm{Cl}_{2}$. Since $\mathrm{PbCl}_{4}{ }^{2-}$ is not very stable $\left(\mathrm{PbCl}_{3}{ }^{-}+\mathrm{Cl}^{-} \rightleftharpoons \mathrm{PbCl}_{4}{ }^{2-} ; \mathrm{k}=8.5 \cdot 10^{-2} \mathrm{lmol}^{-1}\right)^{16}$ the product formation $(\phi=$ 0.21 at $\lambda_{\text {irr }}=313 \mathrm{~nm}$ ) occurs according to the stoichiometry :

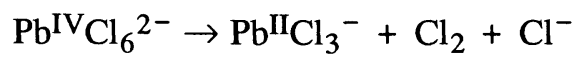

As indicated by the spectral variations (Figure 3 ) this photolysis is a clean reaction which can be driven to completion. Although no attempt was made to detect intermediates the primary photochemical step may yield $\mathrm{Pb}$ III.

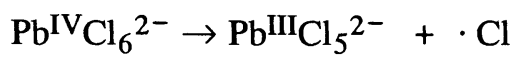

This assumption is based on the observation that the flash photolysis of $\mathrm{PbCl}_{4}$ generates $\mathrm{PbCl}_{3}$ and $\cdot \mathrm{Cl}$ as primary products. ${ }^{17}$ The formation of $\mathrm{Pb}^{2+}$ takes place only in secondary reactions.

The tetrahedral anion $\mathrm{TlCl}_{4}{ }^{-}$undergoes the photochemical elimination of $\mathrm{Cl}_{2}$ in deaerated aqueous solution. ${ }^{12}$ In order to prevent an aquation of this complex the photolysis was carried out in solutions saturated with $\mathrm{KCl}$. Light absorption by the longest-wavelength LMCT band $\left(\lambda_{\max }=247 \mathrm{~nm}, \varepsilon=15850\right)$ of $\mathrm{TlCl}_{4}{ }^{-}$led to the formation of $\mathrm{Tl}^{+}$with a quantum yield $\phi=$ $4.5 \cdot 10^{-3}$ at $\lambda_{\text {irr }}=254 \mathrm{~nm}$. 


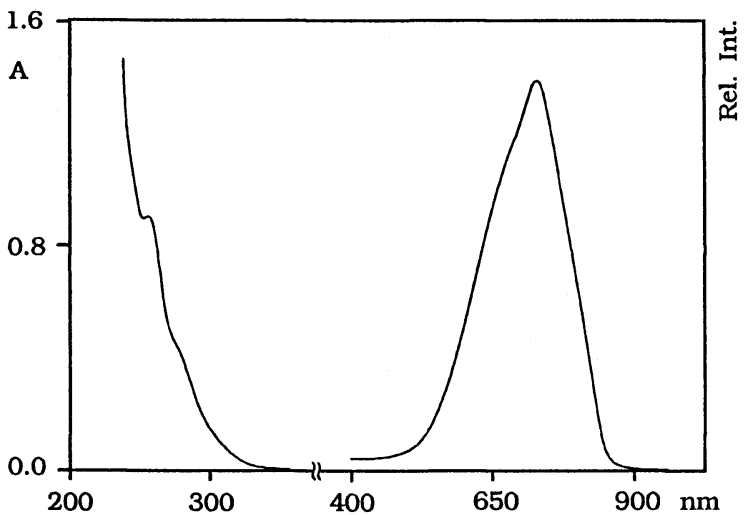

Figure 5 Electronic absorption (left side) and emission (right side) spectra of $\left[\mathrm{NEt}_{4}\right] \mathrm{SbCl}_{4}$ in $\mathrm{CH}_{3} \mathrm{CN}$ at room temperature, 1-cm cell. Absorption: $2.54 \cdot 10^{-4} \mathrm{M}$;

Emission: $5.0 \cdot 10^{-4} \mathrm{M}, \lambda_{\text {exc }}=290 \mathrm{~nm}$

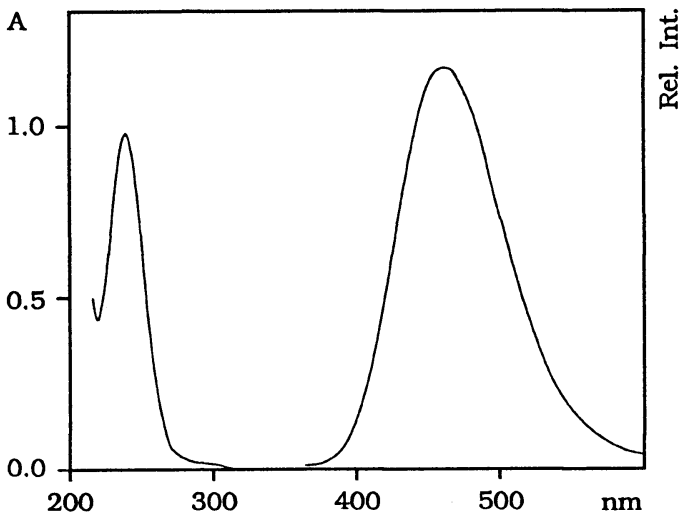

Figure 6 Left side: Absorption spectrum of $2.17 \cdot 10^{-4} \mathrm{M} \mathrm{TICl}$ in saturated aqueous $\mathrm{KCl}$ solution (4.0 M). Right side: Emission spectrum of $4.61 \cdot 10^{-5} \mathrm{M} \mathrm{TICl}$ in saturated aqueous $\mathrm{KCl}$ solution $(4.0 \mathrm{M})$ at room temperature, $1-\mathrm{cm}$ cell, $\lambda_{\text {exc }}=254 \mathrm{~nm}$.

Metal ions with a $s^{2}$ configuration may be photoreduced or photooxidized. Oxidizing $s^{2}$ complexes such as $\mathrm{TeCl}_{6}{ }^{2-}$ have LMCT states at accessible energies. ${ }^{11,12}$ LMCT excitation of this complex in $\mathrm{CH}_{3} \mathrm{CN}$ led to a reductive elimination $\left(\phi=10^{-2}\right.$ at $\left.\lambda_{\mathrm{irr}}=254 \mathrm{~nm}\right)$ according to the equation:

$$
\mathrm{Te}^{\mathrm{IV}} \mathrm{Cl}_{6}{ }^{2-} \rightarrow \mathrm{Te}^{\mathrm{II}} \mathrm{Cl}_{4}{ }^{2-}+\mathrm{Cl}_{2}
$$

Chlorine was detected and determined spectrophotometrically as $\mathrm{Cl}_{3}{ }^{-}\left(\lambda_{\max }=231 \mathrm{~nm}\right) .{ }^{18}$

The majority of $\mathrm{s}^{2}$ ions are reducing and less oxidizing. These $\mathrm{s}^{2}$ ions such as $\mathrm{Tl}^{+}, \mathrm{Sn}^{2+}$, and $\mathrm{Sb}^{3+}$ are photooxidized by $\mathrm{O}_{2}$ to $\mathrm{Tl}^{3+} 14,19, \mathrm{Sn}^{4+} 14,20$, and $\mathrm{Sb}^{5+21,22}$ according to the equation:

$$
\mathrm{M}^{\mathrm{n}+}+\mathrm{O}_{2} \rightarrow \mathrm{M}^{(\mathrm{n}+2)+}+\mathrm{O}_{2}^{2-}
$$

These photoreactions which have been known for 50 years are not only interesting in their own right but are also of considerable importance for industrial applications such as the electroless metal deposition. ${ }^{20}$ Surprisingly, the nature of the reactive excited state and the mechanism of photooxidation has not been studied until recently. ${ }^{22} \mathrm{~A}$ detailed investigation was carried out with $\mathrm{SbCl}_{6}{ }^{3-}$ in $\mathrm{CHCl}_{3}$. Analogous results were obtained with $\mathrm{Tl}^{+}$in aqueous chloride. ${ }^{12}$ First observations on the photooxidation of $\mathrm{Tl}^{+}$were reported by Kirkbright et al. ${ }^{19}$

Upon addition of $\mathrm{TlCl}$ to concentrated aqueous solutions of $\mathrm{KCl}$ a chloro complex of unknown composition is formed. This complex is characterized by an absorption $\left(\lambda_{\max }=240 \mathrm{~nm}, \varepsilon=\right.$ 4516) and an emission (Figure 6) at $\lambda_{\max }=464 \mathrm{~nm}\left(\phi=0.88, \tau=0.62 \cdot 10^{-6} \mathrm{~s}\right.$ in the absence of $\left.\mathrm{O}_{2}\right){ }^{23}$ The absorption leads directly to the population of the emitting sp excited state ( ${ }^{3} \mathrm{P}_{1}$ of the free $\mathrm{Tl}^{+}$ion). Upon exposure to air the phosphorescence is quenched to $\phi=0.1$ at an oxygen concentration of $10^{-4} \mathrm{M}$. Simultaneously, these solutions become light sensitive. The photolysis proceeds according to the stoichiometry $\left(\phi=3.3 \cdot 10^{-2}\right.$ at $\left.\lambda_{\mathrm{irr}}=254 \mathrm{~nm}\right)$ :

$$
\mathrm{Tl}^{+}+4 \mathrm{Cl}^{-}+2 \mathrm{H}^{+}+\mathrm{O}_{2} \rightarrow \mathrm{Tl}^{\mathrm{III}} \mathrm{Cl}_{4}^{-}+\mathrm{H}_{2} \mathrm{O}_{2}
$$

The spectral changes which are associated with this photoreaction appear as the reversal of those which were observed during the photolysis of $\mathrm{TlCl}_{4}^{-}$(see above). 
The photooxidation of $\mathrm{Tl}^{+}$by oxygen in the presence of $\mathrm{Cl}^{-}$is assumed to proceed according to the following simplified reaction scheme:

$$
\begin{aligned}
& \mathrm{Tl}^{+}+\mathrm{h} \nu \rightarrow \mathrm{Tl}^{+*} \\
& \mathrm{Tl}^{+*} \rightarrow \mathrm{Tl}^{+}+\mathrm{h} \nu \\
& \mathrm{Tl}^{+*} \rightarrow \mathrm{Tl}^{+}+\text {heat } \\
& \mathrm{Tl}^{+*}+\mathrm{O}_{2}+4 \mathrm{Cl}^{-}+2 \mathrm{H}^{+} \rightarrow \mathrm{Tl}^{\mathrm{III}} \mathrm{Cl}_{4}{ }^{-}+\mathrm{H}_{2} \mathrm{O}_{2}
\end{aligned}
$$

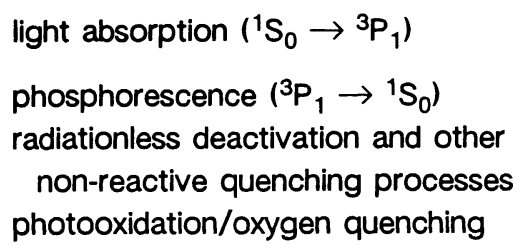

The quantum yield of photooxidation is calculated to be $\phi=0.9$ if the emission data are applied to this kinetic scheme. However, since the experimental photooxidation quantum yield was only $\phi=0.03$ oxygen quenching leads only partially to the photooxidation or the photooxidation is partially reversed by an efficient back electron transfer.

In the presence of an excess of oxygen and chloride a photostationary state is established since $\mathrm{Tl}^{+}$is photooxidized and $\mathrm{Tl}^{3+}$ photoreduced. ${ }^{12}$ The overall reaction

$$
\mathrm{O}_{2}+2 \mathrm{HCl} \rightarrow \mathrm{H}_{2} \mathrm{O}_{2}+\mathrm{Cl}_{2}
$$

proceeds then as a photocatalysis.

\section{OUTLOOK}

The photochemistry of main group metal complexes seems to become an important part of inorganic photochemistry. While considerable progress has been achieved with simple coordination compounds the photochemistry of main group organometallics has not yet been studied systematically although sporadic observations have been reported. With regard to potential applications the photocatalysis by $\mathrm{s}^{2} / \mathrm{s}^{0}$ metal ion redox pairs is anticipated to play an important role in the future. The dehydrodimerization of organic compounds by atomic mercury in the gas phase ${ }^{24}$ as well as in solution ${ }^{25}$ may be a first example of such a photocatalysis. Although the mechanism of this photolysis is largely unknown the redox pair $\mathrm{Hg}\left(\mathrm{s}^{2}\right) / \mathrm{Hg}^{2+}\left(\mathrm{s}^{0}\right)$ could act as photocatalyst. The conversion and chemical storage of solar energy might be another attractive application of the photocatalysis by $\mathrm{s}^{2} / \mathrm{s}^{0}$ systems. Finally, it should be kept in mind that most main group metal compounds absorb only UV light. It is desirable to photosensitize reactions of such compounds for visible light. That this is possible has been shown in a few cases. For example, the photocatalytic oxidation of alkenes was achieved with visible light by using antimony porphyrins as sensitizers and catalysts. ${ }^{26}$ However, more studies are needed to fully understand and optimize such useful photoreactions.

\section{Acknowledgements}

Support of this research by BMFT (Grant 0329075A) and the Deutsche Forschungsgemeinschaft (Grant Vo 211/8-1) is gratefully acknowledged. We thank P. Huber for emission lifetime measurements.

\section{REFERENCES}

(1) (a) Balzani, V.; Carassiti, V. Photochemistry of Coordination Compounds; Academic Press: New York, 1970.

(b) Concepts of Inorganic Photochemistry; Adamson, A. W., Fleischauer, P. D., Eds.; WileyInterscience: New York, 1975.

(c) Ferraudi, G. J. Elements of Inorganic Photochemistry; Wiley-Interscience: New York, 1988.

(2) Vogler, A.; Paukner, A.; Kunkely, H. Coord. Chem. Rev. 1990, 97, 285. 
(3) Albright, T. A.; Burdett, J. K.; Whangbo, M.-H. Orbital Interactions in Chemistry; Wiley: New York, 1985.

(4) (a) Gillespie, R. J.; Nyholm, R. S. Q. Rev. Chem. Soc. 1957, 11, 339.

(b) Gillespie, R. J. Molecular Geometry; Van Nostrand Reinhold: London, 1972.

(c) Gillespie, R. J.; Hargittai, I. The VSEPR Model of Molecular Geometry; Allyn and Bacon: Boston, 1991.

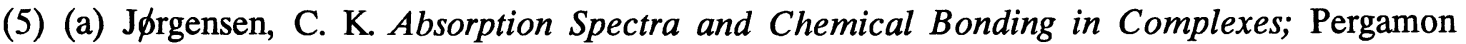
Press: Oxford, 1964.

(b) Jørgensen, C. K. Oxidation Numbers and Oxidation States; Springer: Berlin, 1969.

(6) Fukuda, A.; Inohara, K.; Onaka, R. J. Phys. Soc. Japan 1964, 19, 1274.

(7) Ranfagni, A.; Mugnai, D.; Bacci, M.; Viliani, G.; Fontana, M. P. Adv. Phys. 1983, 32, 823.

(8) Becht, A. diploma thesis; University of Regensburg, 1990.

(9) (a) Pyykkö, P. Chem. Rev. 1988, 88, 563.

(b) Pyykkö, P. Inorg. Chem. 1991, 30, 2781.

(10) Nikol, H.; Vogler, A. J. Am. Chem. Soc. 1991, 113, 8988.

(11) (a) Couch, D. A.; Wilkins, C. J.; Rossman, G. R.; Gray, H. B. J. Am. Chem. Soc. 1970, 92, 307.

(b) Stufkens, D. J. Rec. Trav. Chim. 1970, 89, 1185.

(12) Paukner, A. Ph. D. thesis; University of Regensburg, 1989.

(13) Kunkely, H.; Paukner, A.; Vogler, A. Polyhedron 1989, 8, 2937.

(14) Pringsheim, P.; Vogels, H. Physica 1940, 7, 225.

(15) (a) Blasse, G. Rev. Inorg. Chem. 1983, 5, 319.

(b) Blasse, G. Prog. Solid St. Chem. 1988, 18, 79.

(16) Nikol, H.; Becht, A.; Vogler, A. submitted for publication.

(17) Blazejowski, J.; Szychlinski, J. J. Photochem. 1979, 10, 45 and references cited therein.

(18) (a) Zimmerman, G.; Strong, F. C. J. Am. Chem. Soc. 1957, 79, 2063.

(b) Katzin, L. I. J. Chem. Phys. 1952, 20, 1165.

(19) Kirkbright, G. F.; Mayne, P. J.; West, T. S. J. Chem. Soc. Dalton Trans. 1972, 1918.

(20) (a) D’Amico, J.F.; De Angelo, M. A.; Henrickson, J. F.; Kenney, J. T.; Sharp, D. J. J. Electrochem. Soc. 1970, 118, 1695.

(b) D'Amico, J. F.; Litt, F. A.; De Angelo, M. A. J. Electrochem. Soc. 1972, 119, 956.

(21) Brüll, W.; Schlägel, H. Z. Anorg. Allg. Chem. 1934, 217, 401.

(22) Vogler, A.; Paukner, A. Inorg. Chim. Acta 1989, 163, 207.

(23) Mayne, P. J.; Kirkbright, G. F. J. Inorg. Nucl. Chem. 1975, 37, 1527.

(24) Brown, S. H.; Crabtree, R. H. J. Am. Chem. Soc. 1989, 111, 2935.

(25) (a) Kuntz, R. R.; Mains, G. J. J. Am. Chem. Soc. 1963, 85, 2219.

(b) Calvert, J. C.; Pitts, J. N. Photochemistry; Wiley: New York, 1966.

(26) Inoue, H.; Sumitani, M.; Sekita, A.; Hida, M. J. Chem. Soc. Chem. Commun. 1987, 1681. 